\title{
Acerca de la inferencia en el intercambio verbal habitual y en la dilogía, el doble mensaje y la alusión
}

\author{
Elisabeth Beniers
}

El presente texto recorre los aspectos pertinentes para la comunicación verbal común, concebida como colaboración entre hablante y oyente o autor y lector, y como tendiente a la desambiguación y la univocidad. Se incluyen hipótesis existentes acerca de la representación mental del léxico y del procesamiento de información accesible por vías diversas, para luego mostrar sobre este fondo algunos recursos retóricos empleados por autores que desean construir discursos polivalentes.

PALABRAS ClAVE: inferencia, interpretación, dilogía.

This work reviews several aspects related to common verbal communication, understood as a successful collaboration between speaker and listener, or author and reader, and as tending to disambiguation and univocality. Hypotheses concerning the mental representation of words and processing of information received through diverse channels are mentioned in order to show on this background some rhetorical resources used by authors who aim to produce polyvalent texts.

KEYWORDS: inference, interpreting, ambiguity. 

Elisabeth Beniers

Universidad Nacional Autónoma de México

\section{Acerca de la inferencia en el intercambio verbal habitual y en la dilogía, el doble mensaje y la alusión}

Hay un consenso bastante general entre los estudiosos de la comunicación verbal en el sentido de que ésta supone cooperación entre los involucrados. ¿Cómo se da esta cooperación? En un primer acercamiento podría pensarse que el oyente de una expresión verbal escucha los sonidos sucesivos correspondientes a los fonemas de las palabras dichas por su interlocutor, y entonces las identifica para luego interpretarlas en su contexto. Un escrutinio más cuidadoso ha demostrado que esto no es posible.

De hecho, la velocidad de habla en una comunicación normal es tal que nuestra capacidad perceptiva no nos permitiría identificar la estructura segmental de las palabras que se nos dirigen. Según Aitchison (Words in the Mind, 209), una producción de 20 segmentos por segundo no sería excepcional, cuando nuestro cerebro no alcanza a procesar ni la mitad en este lapso. También dificulta la identificación de segmentos la gran variabilidad acústica de la señal. Los sonidos varían según el contexto de aparición y es difícil aislarlos del continuo sonoro (Jarvella y Meijers apud Aitchison, 209). A esto se añade que los grados de nitidez en la pronunciación también varían y que con frecuencia hay ruido ambiental. 
La comprensión de lo que escuchamos se produce entonces por otras vías. Más bien se reconoce una palabra al elegir de la memoria la que mejor cuadra a un tramo del flujo sonoro que se está recibiendo. Se hacen aproximaciones sobre la base de comparar las configuraciones sonoras oídas y las del léxico memorizado. ${ }^{1}$ Suponer la existencia de un proceso de esta naturaleza implica manejar ciertas hipótesis acerca de la manera como almacenamos las unidades léxicas, es decir, sobre el llamado léxico mental, y sobre la manera de recuperarlas. En las últimas décadas se han dedicado numerosas investigaciones lingüísticas, psicolingüísticas, neurolingüísticas y computacionales a dilucidar esta cuestión. La obra citada de Aitchison registra un centenar de ellas. ${ }^{2}$ Gracias a esto existen algunas nociones ge-

${ }^{1}$ No me voy a referir aquí al debate en curso acerca de si se almacenan en el léxico mental formas flexionadas o no.

${ }^{2}$ Entre ellas se encuentran: G.T.M. Altmann, Cognitive Models of Speech Processing: Psycholinguistic and Computational Perspectives, Cambridge, Mass., MIT Press, 1990; G.T.M. Altmann y R. Shillcock, Cognitive Models of Speech Processing, Hove, Lawrence Erlbaum, 1993; W. Bechtel y A. Abrahamsen, Connectionism and the Mind: An Introduction to Parallel Processing in Networks, Oxford, Basil Blackwell, 1991; B. Butterworth, Language Production, vol. 1, New York, Academic Press, 1980; R.A. Cole, Perception and Production of Fluent Speech, Hillsdale, N.J., Lawrence Erlbaum Associates, 1980; G.S. Dell, "A SpreadingActivation Theory of Retrieval in Sentence Production", Psychological Review 93, 1986, 283-321; G.S. Dell, "The Retrieval of Phonological Form in Production: Test of Predictions from a Connectionism Model", Journal of Memory and Language 27, 124-142; G.B. Flores d'Arcais y R.J. Jarvella, The Process of Language Understanding, New York, Wiley, 1983; U.H. Frauenfelder y L.K. Tyler, Spoken Word Recognition, Cambridge, Mass., mit Press, 1987; V.A. Fromkin, "The Lexicon: Evidence from Acquired Dyslexia”, Language 63, 1987, 1-22; J.L. Garfield, Modularity in Knowledge Representation and Natural-Language Understanding, Cambridge, Mass., MIT Press, 1989; W.J.M. Levelt, Lexical Access in Speech Production, Oxford, Basil Blackwell, 1993; W.D. Marslen-Wilson, Lexical Representation and Process, Cambridge, Mass., MIT Press, 1989; J.L. McClelland, y D.E. Rumelhart, Parallel Distributed Processing: Explorations in the Microstructure of Cognition, Vol. 2: Psychological and Biological Models, Cambridge, Mass., MIT Press, 1986; J.P. Stemberger, "Wordshape Errors in Language Production”, Linguistics 35, 1990, 123-157; L.K. Tyler, W.D. Marslen-Wilson, J. Rentoul y P. Hanney, "Continuous and Discontinuous Access in Spoken Word-Recognition: The Role of Derivational Prefixes", Journal of Memory and Language 27, 1988, 368-381. 
nerales y cierto consenso, desde luego sin poder hablar de un conocimiento cabal.

Se sabe que se almacenan palabras completas ${ }^{3}$ y que esto se hace de dos maneras, de forma coincidente con la definición saussureana del signo linguiístico como entidad de dos caras: una como entidad semántico-sintáctica, o sea, de significado léxico dotado de clase gramatical, y otra como figura sonora o imagen acústica. Se trata de dos módulos separados, con organización interna propia, relacionados entre sí de manera flexible. Dejo de lado aquí las palabras funcionales que pertenecen a clases cerradas y sirven a los enlaces sintácticos. Según parece, constituyen un acervo aparte de las palabras plenas o de contenido, propiamente léxicas.

En el área semántica parecen desempeñar un papel importante en la organización del módulo los prototipos, los campos semánticos y las clases de palabras, así como ciertas jerarquías de abstracción, relaciones de concurrencia en el discurso y de coordinación en el campo léxico. Todo ello da lugar a extensas redes de intercomunicación entre las unidades en el cerebro.

Para hablar, se hará el camino de la intención comunicativa hacia la estructura sintáctica y los significados léxicos más apropiados y de ahí a los significantes. Para interpretar el habla escuchada, se procesa material sonoro haciéndolo coincidir con las imágenes acústicas almacenadas más cercanas e identificando los valores semánticos asociados. ${ }^{4}$

Ninguno de estos procesos es directo e inequívoco. Suele haber varios significados léxicos capaces de expresar una misma intención y gran número de estructuras sintácticas para hacerlo. Por el lado formal, las secuencias sonoras se parecen entre sí, y varias formas suelen "acudir" a la memoria al escuchar el habla; de entre ellas se irán desechando posteriormente las que no son

${ }^{3}$ A la vez que se remite de las entradas de ese acervo a un módulo de recursos morfológicos para analizar palabras y construir otras.

${ }^{4}$ Cfr. por ejemplo, Mel'čuk, Vers une Linguistique sens-texte. 
compatibles semántica o sintácticamente con el resto del enunciado o con el contexto situacional. Cuando varios de los elementos léxicos evocados son compatibles llegan a producirse cruces al hablar, es decir, se pronuncian ambos elementos fusionados. Se podría, por poner un ejemplo, pronunciar alabo por tener presente a la vez alabanza y halago. Otras veces sucede que se adelanta en la pronunciación o en la escritura un término evocado por su similitud fonológica con el que se pretendía producir, sin ser semánticamente apropiado. Esto puede ocurrir cuando se trata de un elemento más frecuente en el uso o con mayor facilidad de pronunciación. Así se producen errores del tipo: "También elaboraron recubrimiento contra la radiación social" (por "radiación solar") (Boletín UNAM-DGCS-356, Ciudad Universitaria, 10 de junio de 2007).

Desde luego, un error así también puede deberse a que una preocupación acerca de fenómenos sociales esté presente en ese momento en la mente del autor, lo cual favorezca la confusión junto con la similitud fonológica de las palabras.

Recientemente escuché a un locutor decir que se había arrastrado a una mujer. De inmediato se corrigió diciendo que se le había arrestado. Una vez más pueden haberse mezclado, para propiciar esta confusión, la similitud fonológica de las dos palabras y los conocimientos o las preocupaciones del hablante acerca de la forma de llevar a cabo un arresto.

En estudios psicolingüísticos se ha visto que los oyentes con frecuencia identifican las palabras mucho antes de que se terminen de pronunciar e incluso antes de que se pronuncien del todo. Se ha comprobado que una palabra puede reconocerse a los 200 milésimos de segundo de su inicio (Marslen-Wilson y Tyler apud Aitchison, 209). ¿Cómo es posible esto, si se supone que se oponen figuras sonoras y aún no se dispone de la que corresponde a la imagen acústica de una palabra? ¿Cómo puede haber servido para su identificación? 
Esto se correlaciona con otro aspecto de la manera de almacenar las unidades léxicas: la representación heterogénea de las diferentes características fonológicas o segmentales. Se ha visto que en la representación de las entradas léxicas de los adultos los fonemas iniciales tienen particular relevancia.

Aparte de tener un dominio inconsciente de las secuencias fonológicas permitidas en nuestra lengua, resulta que recordamos mejor los elementos iniciales y finales de las palabras que el resto. Es decir, éstos son más prominentes en su representación. Por lo general hay también una buena conciencia intuitiva de la estructura silábica de las unidades léxicas, y sobre todo del ritmo, es decir, de la fuerza relativa de las sílabas al interior de la palabra. De esta manera, las unidades léxicas adquieren un contorno más relevante que los segmentos fonológicos individuales en la memoria; el ordenamiento al interior del módulo formal ocurre sobre la base de similitudes en estos aspectos. Por ejemplo, en el primer error citado arriba (solar / social) se ve que se conserva el elemento inicial y el patrón silábico y acentual de la palabra meta, así como cierto rasgo fonético del elemento final (ambos son laterales). Por lo general, así ocurre cuando se pronuncia una palabra por otra: se conserva la estructura rítmica de la palabra meta y el segmento inicial (Viso e Igoa, "Autonomy of Phonological Encoding", 171) citan, por ejemplo: [pes'kado] por [pei'nado]; [kon'sulta] por [kon'dukta]. Cuando no sucede así, suele añadirse o perderse alguna sílaba inacentuada.

Posiblemente ahí esté también la explicación de por qué reconocemos el lenguaje aun cuando la transmisión se da con interrupciones intermitentes o a través de un texto trastocado o mutilado: unos pocos indicios bastan para el reconocimiento de los elementos léxicos.

Cada perfil o contorno compatible con una entrada léxica evoca, por lo general, varias entidades similares entre sí, de las que se irán desechando paulatinamente las menos compatibles con 
el contexto. La imagen más acertada para representar estos procesos parece ser la de la estimulación eléctrica de circuitos que se activan o desactivan sucesivamente a gran velocidad, y donde cada elemento estimulado irradia hacia otros, hasta definirse una versión como la más fuerte.

Ahora bien, lo anterior todavía no explica cómo puede identificarse una palabra aun antes de que se pronuncie. Para esto habrá que dar un paso hacia atrás y tomar una perspectiva más amplia desde la cual observar el proceso de comunicación.

Cualquier diálogo ocurre en circunstancias que le dan ya cierta predeterminación o delimitación; se crean expectativas a partir de esas circunstancias. No se espera cualquier tipo de comunicación en cualquier lugar y momento. La hora, el lugar, el tipo de relación entre los interlocutores determinan en alguna medida los temas de conversación, y éstos, a su vez, cierto vocabulario. Una vez comenzado el intercambio, la aparición de muchas palabras será perfectamente previsible en el transcurso. A esto se suma la redundancia propia de la lengua, es decir, el hecho de que en determinado contexto hay una mayor probabilidad de ocurrencia de unos elementos sobre otros. ${ }^{5}$

El interlocutor pone en juego mucho más que su conocimiento del léxico. Va construyendo mentalmente el enunciado, ade-

\footnotetext{
${ }^{5}$ Agradezco a uno de mis dictaminadores anónimos el haber llamado mi atención sobre los estudios de disponibilidad léxica como posible marco de referencia para los fenómenos aquí aludidos. La noción de léxico disponible se relaciona con la activación de cierto vocabulario en torno a un tema o centro de interés como los que evocan los diversos tipos de situación comunicativa. Haciendo referencia a estudios hechos en Francia y México (de Georges Gougenheim y Juan López Chávez, respectivamente), Luis Fernando Lara resalta el carácter social de la competencia léxica: "De los resultados obtenidos por los grupos francés y mexicano, resulta notable que los miembros de cada grupo de informantes, clasificados por edades, por oficios, por nivel de escolaridad, por región, etc., en un estadio contemporáneo de la lengua histórica, tienden a recordar los mismos vocablos y aproximadamente en el mismo orden. Es decir que, aun cuando la asociación mental es un fenómeno individual, los miembros de cada grupo de informantes coinciden en el mismo tipo de asociaciones, lo cual es un importante indicio de la socialidad del léxico en un momento determinado de la historia" (Curso, 174).
} 
lantándose al hablante, aportando al proceso no sólo el léxico y su manejo de la sintaxis ${ }^{6}$ de la lengua que tienen en común. Conoce también ciertas convenciones que rigen la comunicación, así como situaciones vitales características. Los estudiosos de la adquisición de segundas lenguas están particularmente conscientes de que existe un factor que puede ser decisivo para que se dé o no la interpretación adecuada: el trasfondo cultural. Diferente origen cultural y diferencias en la experiencia de vida afectan la interpretación.

Entender algo que se nos dice implica entonces muchísimo más que reconocer señales lingüísticas ante un posible trasfondo de otros ruidos. El segmentar el flujo sonoro reconociendo elementos léxicos y prosódicos, construir una estructura gramatical y textual que - junto con los significados léxicos y los valores asociados a ellos - guíe la construcción de un sentido requiere de un proceso de inferencia en el que se construye una interpretación, y este proceso se lleva a cabo en varios niveles tanto de orden linguiístico como cultural y de conocimiento del mundo. Interviene, además, el interés del oyente, quien selecciona o crea un sentido — más que recibirlo pasivamente — donde interpreta el por qué de un enunciado, su intencionalidad y los motivos del hablante con relación a él mismo.

Ahora bien, no reaccionamos únicamente al contenido informativo de un enunciado; éste puede también evocar sentimientos y estados de ánimo: lo relacionamos con la propia expe-

\footnotetext{
${ }^{6}$ La realidad psicológica de la construcción de representaciones sintácticas se hace evidente cuando se consideran homófonos sintácticos que pueden dar lugar al manejo de estructuras alternativas, lo que ocasionalmente induce a error o se aprovecha para juegos verbales que implican resegmentación. Xavier Villaurrutia hace un uso poético de esta posibilidad en su "Nocturno en que nada se oye", donde destaco las versiones alternativas: "[...] Y en el juego angustioso de un espejo frente a otro / cae mi voz / y mi voz que madura / y mi voz quemadura / y mi bosque madura / y mi voz quema dura / como el hielo de vidrio / como el grito de hielo / aquí en el caracol de la oreja / el latido de un mar en el que no sé nada/ en el que no sé nada [...]" (Nostalgia de la muerte, 53-54).
} 
riencia y tomamos partido haciendo una valoración personal de lo que se nos dice, tanto con respecto al contenido como a la forma en que éste se expresa, y tomamos decisiones acerca de cómo responder con base en todo ello. ${ }^{7}$

Para representarse el proceso de aprovechamiento de información de distintas fuentes se puede recurrir a la tesis de la modularidad de la mente de Fodor (Modularity), según la cual la mente consta de diversos módulos de entrada que se ocupan de procesos encapsulados, específicos de algún dominio particular, y de un sistema central que maneja procesos globales abiertos. La tarea de los módulos de entrada es convertir representaciones sensibles provenientes de procesos perceptivos y lingüísticos en un lenguaje común de pensamiento. El sistema central se encarga del razonamiento consciente y de la solución de problemas.

A la primera fase de asignación de representaciones semánticas a figuras acústicas sigue la fase inferencial, en la que se toman estas representaciones más las sintácticas como datos de entrada para el procesador central y se completa la estructura lógica mediante procesos de desambiguación, de asignación de referencia y de enriquecimiento conceptual, con la añadidura de material omitido para derivar formas proposicionales ( $c f r$. Fodor, Modularity, 88-93). Si, por ejemplo, una estudiante en un pasillo de la facultad le dice a otra: "Ahí viene", la interlocutora no recibe más información del enunciado que la de que una persona se dirige hacia donde están ellas desde una distancia mediana.

Para asignar referencia a "Ahí", es probable que siga la dirección de la mirada o de un movimiento de cabeza de su compañera; es decir, aprovecha y procesa información visual, lo que también podría servirle para asignar referencia a la marca morfológica del sujeto de "viene", del cual sólo está indicado

${ }^{7}$ Cfr. Solmecke, Texte hören. 
que se trata de un ser individual. Pero es más probable que recurra a lo que se dijo en un contexto inmediato anterior, o a datos que guarda en su memoria acerca del personaje, información que podría ser del tipo:

'Es el profesor que le ofreció trabajo' o

'Es el profesor que la acaba de reprobar' o

'Es el muchacho del que se acaba de separar', etc.

y que complete el sentido proposicional: 'A la altura del primer salón viene Juan, quien acaba de dejar de ser novio de Anita', lo que probablemente la capacite para sacar conclusiones del tipo: 'No querrá encontrarse con él en este momento', y proponer, por ejemplo: “¡Vámonos!”.

Del lado del emisor, toda esta labor de desciframiento e interpretación se corresponde con una adaptación a los conocimientos del oyente, tanto generales como específicos para el tema y las capacidades del receptor, así como por el respeto a lo que se ha llamado las máximas de conversación de Grice ("Logic and conversation"). Estas máximas para una conversación racional se engloban bajo la norma general de hacer una aportación a la conversación tal como sea requerida por el propósito y la dirección del intercambio en el momento en que sucede. ${ }^{8}$

\section{${ }^{8}$ La máxima de cantidad:}

1. Tan informativa como se necesita en el momento del intercambio.

2. No más informativa de lo que se requiere.

Máximas de calidad:

La supermáxima: Trata de hacer una contribución que sea verdadera.

1. No digas lo que creas falso.

2. No digas algo que no te conste suficientemente.

La máxima de relación:

1. Sé relevante.

Las máximas de modo:

La supermáxima: Sé perspicuo, transparente.

1. Evita expresiones oscuras.

2. Evita la ambigüedad.

3. Sé breve (evita la prolijidad innecesaria).

4. Sé ordenado. 
Una vez lograda la interpretación, ésta todavía se somete a la confirmación por el criterio de la relevancia comunicativa. Ello puede comprobarse observando el comportamiento del receptor ante una expresión de las llamadas gardenpath, donde primero se induce al oyente o lector a configurar cierto análisis semántico-sintáctico, para luego obligarlo a volver hacia atrás y analizar el mismo material con otra estructura. Son recursos muy usados en chistes y en la publicidad, por ejemplo.

Actualmente se escucha en México un anuncio radiofónico que reza: “¿Con qué frecuencia camina?”. Esta secuencia se analiza de forma muy natural como el verbo caminar con el sentido de 'andar', más un complemento modal representado por frecuencia en el sentido de 'repetición' introducido por la preposición con, en construcción interrogativa cuantitativa: ‘¿Qué tan seguido camina?’ o ‘Cada cuándo camina?’ Pero al escuchar la respuesta: "Con la 96.1 de Frecuencia Modulada, Radio Universidad", el escucha se ve en la necesidad de volver sobre su anterior lectura y convertir la interpretación de frecuencia con valor de 'número de repeticiones en un plazo dado' en algo equivalente a 'frecuencia radiofónica' y el enunciado todo en ‘¿Qué frecuencia radiofónica escucha mientras camina?’ o ¿Con qué frecuencia radiofónica se acompaña?’ De esta manera la primera oración del anuncio queda convertida en calambur.

Por cierto, se emiten variantes de este anuncio: “¿Con qué frecuencia se relaja?” y “Con qué frecuencia rejuvenece?”, todas gardenpaths por el contexto subsecuente. Es decir, la respuesta dada brinda un contexto lingüístico que muestra la no-relevancia comunicativa de la primera interpretación del enunciado inicial, obligando al radioescucha a intentar una nueva.

Los gardenpaths son construcciones que contravienen la "máxima de calidad de modo" (de Grice) en el sentido de no hacer lo más accesible la información por la forma de presentación. A cambio, con estas estructuras se logra un efecto especial, de- 
bido a que el receptor tiene que hacer un mayor esfuerzo en el desciframiento al volver sobre sus pasos: ello redunda en una mayor retención de lo que se dijo. Esto es precisamente lo que pretende la publicidad, mantener la atención sobre aquello que se menciona.

Lo común en la comunicación verbal cotidiana, en todo caso, es ir resolviendo ambigüedades, desactivando opciones débiles y optar por una versión definitiva en el proceso de construcción de la interpretación.

Llama la atención entonces que sea posible construir dilogías, dobles mensajes o discursos mantenidos deliberadamente ambiguos, como en efecto sucede. Éste es el fenómeno que quiero enfocar en lo que sigue. La pregunta es: ¿cómo es posible que se mantenga activada una doble o múltiple versión de un mismo texto, cuando esto es contrario al proceso natural de comprensión? ¿De qué manera se invita u obliga al oyente a ello?

\section{La dilogía, ${ }^{9}$ el doble mensaje, el implícito}

Siempre que se contraviene deliberadamente alguna regularidad en el funcionamiento de la lengua pueden obtenerse efectos especiales. Así sucede también con la dilogía. Trataré de ver cómo afecta ésta el proceso de inferencia y qué efecto podrá causar sobre el receptor.

Helena Beristáin, en su artículo "Enclaves, encastres, traslapes, espejos, dilataciones (la seducción de los abismos)" describe una serie de recursos que provocan lecturas diversas de

\footnotetext{
${ }^{9}$ Es decir, "el uso deliberado de un signo o una misma forma en un mismo enunciado o en enunciados sucesivos con distinto valor o acepción, por ejemplo: 'Que quien tal cabeza trae, será en mi casa cabeza"' (Beristáin, Diccionario de Retórica, 154). La polisemia natural de las palabras juega un papel facilitador en muchos juegos verbales tal como se observa aquí, en los gardenpaths y en otros casos que menciono en el presente trabajo.
} 
textos literarios, en particular a través de las construcciones en abismo que producen la multiplicación del texto como en espejo o en refracción. Cuando se escribe "la historia del escritor en trance de escribir que escribe" se invita al lector a leer el texto "como relato de una aventura y como la aventura de un relato" ("Enclaves, encastres", 244). Beristáin describe los efectos de la construcción en abismo como sigue:

Las estructuras abismadas capturan la atención de quien las percibe, como lo hace un enigma cuya elucidación se nos revela, de pronto, como indispensable [...] su poder de seducción hipnotiza, pues atrae y mantiene prolongadamente el interés curioso, intrigado y meditativo del receptor. En otras palabras, la estructura abismada crea tensión y suspenso, además de funcionar como 'forma obstruyente' (obscuridad) que prolonga el goce artístico proveniente en este caso del contacto con la naturaleza enigmática de la arquitectura de la obra (248).

Es decir, el obstruir deliberadamente el acceso a una interpretación obvia puede intensificar el goce estético. En estos textos artísticos se introducen nuevas perspectivas que producen versiones o percepciones adicionales de ellos. En géneros menos exigentes, de consumo cotidiano, las dobles lecturas se provocan con otros recursos.

Entre otros recursos, el periodista de La Jornada Julio Hernández López aprovecha en su columna del 25 de junio de 2007 el poder de evocación de los fonemas iniciales de una palabra, para lograr una lectura por lo menos doble de "Jorge Luis Borguetti': 'Jorge Luis Borges' y 'Jared Borgetti' (un conocido jugador de futbol soccer). Es también posible que aluda a un error cometido por el ex presidente Vicente Fox al referirse al célebre escritor como José Luis Borgues, lo que implicaría una tercera lectura. Dice: "Nada conmueve al siempre triunfador Hugo, ni siquiera perder el Guardado (Andrés) que se ha desvanecido y corre peligro de inestabilidades posteriores (nada 
que ver con los juegos hacendarios de Carstens y los riesgos de inflación) ni las lesiones del adelantado poeta del remate aéreo, Jorge Luis Borgetti".

En el contextoinmediato anteriora la mención del nombre trastocado ya da una mezcla de elementos caracterizadores de los dos personajes al hablar del "adelantado poeta del remate aéreo", preparando así al lector para encontrarse con el doble mensaje y jugando con diversos valores de adelantado, 'el que está adelante' como el delantero Jared Borgetti, pero también como el que tiene algún rango o posición de privilegio como corresponde a usos antiguos del término adelantado, y conviene a la posición social de un escritor destacado, o incluso, como dice el Diccionario de la Real Academia, con el de 'capitán general en tiempos de guerra'.

En la oración donde aparecen estas referencias hay otras dilogías. Al decir perder el Guardado en vez de a Guardado, apellido del valioso medio de la Selección Mexicana de futbol quien se desmayó después de chocar de cabeza con otro jugador, introduce la acepción 'ahorro' (el guardado, 'pequeña reserva que crean las amas de casa con el cambio de las compras cotidianas'), de donde arranca una línea de crítica de la economía política que desarrolla al usar también en dos sentidos la palabra inestabilidades, tanto referida a la inestabilidad física o neurológica del jugador como a la económica de la nación, que retoma con la observación irónica, en un aparte entre paréntesis, sobre las medidas del Ministro de Hacienda.

Mantiene de esta manera al lector ocupado en el desciframiento simultáneo de dos mensajes paralelos que podrían ser como sigue:

a) 'El entrenador de la Selección de futbol de México es un optimista sin motivo al tener que renunciar a Guardado y Borgetti por lesiones'.

b) 'Las reservas se están desvaneciendo con los juegos hacendarios del ministro y hay riesgos de inestabilidad e inflación'. 
Desde luego, como a cualquier inferencia sobre un enunciado, el receptor tiene que aportar sus conocimientos lingüísticos y del mundo. De hecho, toda la columna de Hernández López de ese día es una alegoría entre futbol y política, entre el comportamiento de los responsables de una y otra área.

Lo que se desprende es que, al igual que en los gardenpaths, se complica la lectura de los textos. Pero mientras que en aquéllos la información conflictiva se introduce de manera sucesiva moviendo a sonrisa y corrección, aquí es simultánea y dispar, lo que desata turbulencia y eventualmente hilaridad y obliga a procesamientos simultáneos; el texto se adensa.

El autor se recrea introduciendo términos ambivalentes o a los que atribuye tal valor al darles el contexto apropiado para ello, frenando así la lectura y obligando también al lector a la especulación. Junto con la mayor densidad ofrece diversión; hay sarcasmo, hay crítica, pero también risa y solidaridad con el lector frente al poder. En resumen, se crea un ambiente de sátira política.

En la emisión del 6 de septiembre de 2006 de la misma columna periodística, Hernández López, por su habilidad para crear el contexto adecuado, evoca simultáneamente dos aspectos que indignaron en ese momento a gran parte de la población con respecto a la resolución de las elecciones presidenciales recién concluidas: el que por unanimidad el Tribunal Electoral del Poder Judicial de la Federación hubiera declarado nimios los delitos electorales perpetrados.

Intitula su contribución "Por una nimiedad". La habría podido intitular "Una nimiedad" y luego indignarse por el hecho de que así se declararan las faltas cometidas, pero para nada hubiera obtenido el mismo impacto que aquí logra al anteponer la preposición por, con lo que inmediatamente se evoca el giro muy usado "por unanimidad", ya que la frecuencia de uso tiene un papel en la disponibilidad mental de los elementos lingüísticos y la similitud fonológica se impone. De esta manera se lee 
a la vez "por unanimidad" y "por una nimiedad", en una especie de constatación caricaturesca que en su simultaneidad supera el carácter lineal del lenguaje, aunque sea por un instante. Con este simple recurso del contexto ha convertido su frase en calambur que ofrece varias lecturas mediante la resegmentación y restructuración con una ligera variante.

En la misma oración emplea un cuasihomófono de electo con el que también expresa su falta de disposición a reconocer al candidato respaldado por el tribunal; lo llama eyecto, logrando así nuevamente una doble lectura.

Por considerar que todas las violaciones al proceso electoral fueron una simple nimiedad (una pequeñez, una insignificancia), los magistrados del Tribunal Electoral del Poder Judicial de la Federación (TEPJF) declararon ayer presidente eyecto a Felipe Calderón [...].

A este periodista, muy dado a los juegos de palabras que introduzcan una nota de humor en su columna de comentario político, nunca le faltan recursos para implicar tales dobles discursos. Así, el 21 de noviembre de 2006 se vale de un refrán:

Los insistentes presagios de fracaso programados como inserción pagada en diarios y estaciones de radio y televisión pretendían "demostrar" que el apoyo popular al tabasqueño habría caído a niveles dignos de lamento. López Obrador habría "derrochado" su capital político, pontificaban los críticos del peje en el ojo ajeno que no ven el calderón en el propio. ${ }^{10}$

logrando así una especie de intertextualidad.

En otras ocasiones simplemente altera la ortografía, así el 4 de julio de 2007, al mencionar los apellidos del Secretario del Trabajo, Lozano Alarcón, quien se vio involucrado en un es-

${ }^{10}$ Hace referencia al sobrenombre de Peje que se ha dado al líder de izquierda Andrés Manuel López Obrador. 
cándalo tras encontrarse varios millones de dólares en efectivo en la casa de un empresario de origen chino, lo escribe "Javier (que Lo Sano lo pasa Al Arcón)", y en su contribución del 5 de julio emplea rasgos de supuesto origen oriental para el nombre del Presidente de la República e hispaniza el apellido del ciudadano de origen chino, dándole de paso un significado:

Puede que todo acabe siendo un malintencionado cuento chino, pero el gobierno de Fe Lee Pe ha reaccionado con nerviosismo y descuido jurídico ante el llegue superlativo (un lle-gón ${ }^{11}$ ) que el mero Día del Mapache Electoral ${ }^{12}$ le ha sido enviado a un presidente made in China desde Estados Unidos (Washington presiona por algo que mister F.C. no quiere cumplir o quiere repartir de distinta manera).

El 2 de julio de 2007, jugando con la sustitución de un solo fonema, logra imponer la lectura múltiple de una frase debido a la disemia de las demás palabras involucradas y las opciones presentes en el ánimo de sus lectores. Dice “¡Hasta mañana, en esta columna que a partir de una frase pronunciada ayer en el Zócalo se pregunta si el país está gobernado por el Telele!" que cabe leer como "si el país está gobernado por el sobresalto" al haber bastantes escándalos y hechos violentos, "por la Tele", ya que escribe con mayúscula como si fuera en referencia al nombre de una televisora o, finalmente, "por el pelele", como ha caracterizado López Obrador al ganador oficial de las elecciones y a quienes le siguen.

Por último, en su entrega del día 23 de julio de 2007 recurre de nuevo al cruce para hacer presentes simultáneamente los nombres de los dos personajes que considera responsables de la re-

${ }^{11}$ El apellido es Ye Gon, o sea homófono de llegón en pronunciación mexicana. Un llegue es un golpe.

${ }^{12}$ El día 2 de julio, aniversario de las elecciones. Se habla del "mapache" como el Defraudador electoral, bautizado así por analogía con el antifaz y la actitud furtiva de los mapaches. 
presión violenta de un movimiento social al poner el título "Feliz es Ulipe", haciendo referencia al gobernador de Oaxaca Ulises Ruiz y Felipe Calderón simultáneamente, y más adelante hablar de la Guerraguetza en vez de la Guelaguetza, la tradicional fiesta oaxaqueña del encuentro de los pueblos. Más adelante dice "Feliz es Ulipe, de apellido Ruiderón".

Se ve así que son muchos los recursos posibles para obligar a manejar dos o más elementos al leer un mismo discurso. Lo esencial es mezclar de manera ingeniosa datos que apunten en una y otra dirección y que no sean reductibles a metáfora, por ejemplo, ni lleguen al extremo de hacer desistir al lector de avanzar en el texto por considerar que se trata de disparates involuntarios: los casi homófonos, los casi sinónimos, los contextos que apuntan en otra dirección que el texto, las grafías alusivas y los cruces.

\section{Dilogía y lenguaje alburero ${ }^{13}$}

El lenguaje alburero es el territorio por excelencia del doble mensaje, donde intervienen todos los recursos de la alusión y del implícito y, desde luego, la dilogía, si bien especializada en los campos semánticos de la sexualidad y la escatología. En el uso del lenguaje alburero se manifiesta la voluntad de divertirse y, eventualmente, divertir a otros mediante la alusión más o menos velada a estos temas. Ésta se instrumenta por muchas vías, por ejemplo, sugiriendo la lectura alterna de una expresión común, como en la canción del compositor popular Chava Flores "Tomando té":

\section{No quiero tomar café}

porque el café quita el sueño,

${ }^{13}$ Agradezco sinceramente la ayuda de Enrique Bonavides con el desciframiento de albures. 
lo que quiero es tomar té, pues tomando té me duermo.

donde con un sutil cambio de acento se escucha "tomándote" y se le asigna un significado sexual que líneas más adelante se hace explícito.

En los clásicos diálogos albureros, aquél que responde a la invitación al albur activa el campo semántico del sexo y de las funciones corporales con su amplio acervo de sinónimos y eufemismos, creados ya en la tradición alburera (Gutiérrez González, Construcción interactiva del albur, 130 y ss.) y afila su ingenio para crear nuevas lecturas con estas implicaciones de cualquier texto inofensivo que vaya construyendo, ya sea por homonimia, paronomasias o reconfiguración de partes de significantes de cualquier expresión.

En lo expuesto al principio del presente trabajo acerca de la organización mental del léxico y del acceso a éste se encuentran elementos que favorecen la presencia simultánea de más de un valor y más de un elemento formal, es decir, de homónimos y casi homónimos, y de más de una unidad semántica, o sea, de sinónimos y casi sinónimos en la mente de los hablantes, lo que facilita la dilogía desde la constitución mental misma.

Puede decirse entonces que en estos casos hay de antemano una disposición a dejar activo el mayor número de conexiones entre elementos léxicos, con la única condición de que puedan relacionarse con los temas en cuestión. Es decir, en este caso se renuncia de entrada a la univocidad y se aprovecha al máximo la condición natural de activación múltiple y extendida. La finalidad es, tal como dice Beristáin, procurarse un rato de diversión.

En el caso ideal hay jugadores, algún otro experto en el público y un auditorio ingenuo e ignorante del código empleado que no se percata de la procacidad de los mensajes intercambiados, brindando así a los albureros el placer de transgredir en las narices de la "gente decente" convenciones y valores establecidos. 
Encontramos expresiones como: "Cuando te veo palpito" o "ya estuvo, no es tubo, es corneta" (Gutiérrez González, Construcción interactiva del albur, 75 y 134), donde se espera una resegmentación del flujo del habla, lo que es común para hacer del mensaje aparentemente inofensivo uno que contenga vocabulario sexual, como cuando en diálogos albureros se refiere "no se apene" a "pene" o "A ver Ga...briel" a "verga". Otro recurso es una pronunciación deliberadamente defectuosa de ciertas palabras como en "Sólo hay de miembrillo y te va a caer bien, porque de comer hay sopa de verguras", etc. ${ }^{14}$ También se alude a situaciones sexuales en expresiones apenas disfrazadas:

- Oiga, compadre, ya está sudando y apenas empezó a comer. - Sí, compadre, estoy sudando por el chile; es que está muy picoso y me está ocasionando acidez.

-Pues hágale como en el comercial, chupe Melox y muerda Melox, para que se le quite. ${ }^{15}$

Estos juegos, como menciona Helena Beristáin ("El Albur", 3 ), incluso han invadido los espacios públicos en forma de anuncios comerciales. Llegó a haber un anuncio gigantesco, de los llamados espectaculares, que mostraba a un hombre de rasgos orientales en trusa y rezaba más o menos así: "Trusas marca $\mathrm{X}$ [la marca comercial] para su mejor elección”, jugando con el fenómeno de la confusión entre dos consonantes (rotacismo), tan característica del habla de los orientales.

En los ejemplos citados se propone también la recuperación de elementos del vasto vocabulario metafórico referido a los órganos sexuales o al acto sexual. Helena Beristáin, quien ha hecho los estudios más acabados sobre la naturaleza del albur

\footnotetext{
${ }^{14}$ Citado en la página electrónica Quid Comunidad Virtual: Cuernavaca <http:// quid.8m.com/albures.htm> (consultada el 2 de marzo de 2008).

${ }^{15}$ Ejemplo citado en el sitio electrónico mencionado en la nota anterior. Cabe señalar que el 'Melox' es un antiácido comprimido en tabletas masticables.
} 
(1997, 2000,2001) en los que se pueden encontrar muchos ejemplos más de lenguaje alburero, menciona coger, clavar, tirarse $a$, como equivalentes de penetrar sexualmente; pájaro, clavo, camote, chorizo, chile, chipotle, nabo, zanahoria, longaniza, salchicha, reata, cuarta por el miembro masculino, y aro, argolla, anillo, agujero como referencia al esfínter anal. Existen otras muchas expresiones metafóricas, como pito, pistola y pelón para el miembro masculino, y chico para el esfínter anal; leche, zumo, baba, para el semen; llorar para eyacular, acomodarse o sentarse para permitir la penetración anal con la que suele amenazarse al interlocutor en los clásicos duelos de albures entre varones ( $c f r$. Beristáin, Diccionario de Retórica, nota 98 , y el anexo ${ }^{16}$ al presente texto).

Más allá del vocabulario metafórico existe también un amplio acervo de vocabulario cifrado, creado expresamente para la alusión sexual, los llamados alburemas. Éste se encuentra con frecuencia en los duelos albureros poco inspirados, donde a los interlocutores les falta ingenio para ir creando las alusiones a partir de cualquier tema que se toque, por lo que entonces recurren a ese léxico trillado de palabras y giros fijos. Un ejemplo de ello se encuentra en el Anexo al presente texto.

Lo cierto es que el lenguaje alburero ejemplifica como ningún otro la vastedad de conexiones existentes dentro del léxico mental y la opción de mantener encendidas todas las ramificaciones formales y semánticas respecto de algún tema y de hacer un uso creativo de ellas. Es la más clara infracción a la máxima de modo de Grice, cuyo efecto hilarante se produce precisamente por la interiorización de esa máxima en la sensibilidad de los hablantes.

En el recorrido hecho en el presente trabajo se reconocen textos variados creados deliberadamente para lecturas múltiples. Las intenciones detrás de esta práctica son tan diversas como

\footnotetext{
${ }^{16}$ Agradezco a Helena Beristáin haberme facilitado el texto del Anexo.
} 
los resultados, desde la procuración de un goce estético más profundo hasta la procacidad y el abuso al incauto, pasando por recursos para llamar la atención y para la creación satírica.

El hecho a tomar en cuenta es que no siempre nos expresamos con la mayor transparencia posible, y una vez interiorizada la máxima conversacional de Grice, puede —como toda norma - infringirse, obteniendo con ello efectos particulares.

\section{Anexo}

Diálogo alburero entre dos cuidacoches o "franeleros" (personas que cuidan automóviles en la vía pública y suelen traer un trapo de franela), un chofer de camioneta de reparto de libros y una cliente de la librería. Ocurre en la puerta de la Librería Gandhi.

El chofer va a estacionarse.

-Espérese tantito a que pasen los coches... Nosotros le echamos aguas ${ }^{17}$ para que se acomode... ${ }^{18}$

- Mejor échense para allá y quédense quietos... ${ }^{19}$ no los vaya a machucar.

- Si quietos estamos... ${ }^{20}$ para que se acomode... ${ }^{21}$

-Pues apártense, que ahí les voy. ${ }^{22}$

—iViene, viene, viene...! (La camioneta golpea un coche: ¡tras!, suena).

— ¿No me dijeron que me viniera?

-Sí, pero usté no quiso que le echáramos aguas. ${ }^{23}$

\footnotetext{
${ }^{17}$ Eyaculamos.

${ }^{18}$ Me las dé (las nalgas).

${ }^{19}$ Esténse dispuestos y colaborando...

${ }^{20}$ Estamos dispuestos.

${ }^{21}$ Nos facilite la penetración.

${ }^{22}$ Facilítenme; los cojo.

${ }^{23}$ Que eyaculáramos.
} 
—Pues si me estaban diciendo "viene, viene"...

- Sí; pero usté se vino rete rápido... yo por eso le advertí: ¡Comódese primero! ${ }^{24}$

- Te voy a acomodar, pero un fregadazo...

-Cálmese, ni fue pa' tanto... mejor véngase de cola poquito a poquito. ${ }^{25}$

(El chofer consigue estacionarse y, al apearse, los franeleros le dicen:)

- ¿Se lo cuidamos, ${ }^{26}$ se lo lavamos ${ }^{27}$ ?

-Mejor nomás échenle un ojito... ${ }^{28}$

- Le vamos a echar hasta dos, pero se pone guapo ${ }^{29}$ con la propina... (El chofer se va y quedan sólo los dos franeleros. Uno de ellos se recarga en uno de esos coches que tienen alarma automática y, cuando se apoya, la sirena comienza a sonar).

— ¡Órale! ¿Ya oístes? Nomás te recargaste y revivió. Lo que no haría si te sentaras bien... ${ }^{30}$

-Pues súbete tú para que veas... ${ }^{31}$

- Para que veas... ponte acá. ${ }^{32}$ Mira lo que viene tras de $t i^{133}$ (Una mujer muy atractiva sale de la librería al escuchar la sirena de su auto).

—No se apure, señorita, aquí éste se recargó... pero se lo estamos cuidando, ${ }^{34}$ ya sabe que estamos aquí para servirle en

${ }^{24}$ Démelas bien primero.

${ }^{25}$ Mejor déjese penetrar poquito a poco.

${ }^{26}$ ¿Se lo atendemos? (Su sexo, entendido como femenino; dándole trato de hembra.)

${ }^{27}$ Cfr. Nota 1.

${ }^{28}$ Presten el ano.

${ }^{29}$ Le vamos a dar hasta dos (cambiando el referente) venidas, pero se perfu$m a \ldots$

${ }^{30}$ Con un mínimo contacto se excitó. Lo que no haría si te dejaras bien...

${ }^{31}$ Pues siéntate en mi regazo para que veas...

${ }^{32}$ Para que veas... acóplate acá.

${ }^{33}$ Mira lo que viene tras de ti... (Alusión a la penetración anal).

${ }^{34}$ Le estamos prestando atención a su sexo... 
lo que quiera... ${ }^{35}$ Usté nomás díganos y le hacemos el trabajo que usté guste... no se va a arrepentir... ¿No quiere que se lo lavemos...?

-No, muchas gracias, ya les dije que no tengo tiempo; nada más pago los libros y me voy.

- Se lo podemos hacer rapidito y va a quedar muy contenta. ${ }^{36}$ (La mujer atractiva vuelve a la librería).

-Ay, hijo, esa vieja está... ¿No te gustaría... o te gusta más l'otra ${ }^{37}$ ?

— ¿La otra? ¿La que tráis siempre en la boca? Ésa mejor quédatela tú, compadre.

-Me gusta ser compartido... te la presto... ${ }^{38}$

-No presumas, hijo... si no alcanza más que para ti... ${ }^{39}$

-Pero te la doy con gusto ${ }^{40}$ (El chofer de la camioneta regresa; los franeleros silban y preguntan:)

- ¿Ya se va, jefe?

-No, aquí me voy a quedar a vivir...

-Como guste: nomás muévase tantito, hágase más para atrás, para que aquí a éste le quepa otro. (El chofer saca la mano por la ventanilla y extiende un peso).

_ ¡Un peso... un peso nada más! Guárdeselo, jefe... a usté le hace más falta y ténga este otro pa'que se lo retaque bien.

\footnotetext{
${ }^{35}$ Estamos aquí para darle satisfacción sexual de la manera en que usted guste...

${ }^{36}$ Puede ser una relación rápida y va a quedar muy contenta.

${ }^{37}$ ¿No te gustaría... o te gusta más l'otra? (Cambiando de referente, la otra: mi pene, mi verga).

${ }^{38}$ Te penetro...

${ }^{39}$ Estás mal dotado, no vales la pena.

${ }^{40}$ Pero te penetro con gusto.
} 


\section{REFERENCIAS}

Aitchison, Jean, Words in the Mind, Oxford, Cambridge, Basil Blackwell, 2a. ed., 1994.

Beristáin, Helena, "Enclaves, encastres, traslapes, espejos, dilataciones (la seducción de los abismos)", Acta Poetica 14-15, 19931994, 235-276.

—_ Diccionario de Retórica y Poética, México, Porrúa, 8 ed., 1997.

—_, "El Albur", en Retórica, Política e Ideología. Desde la Antigüedad hasta nuestros días. F. Cortés Gabaudan, G. Hinojo Andrés y A. López Eire (eds.) Salamanca, Logo, vol. III, 2000, 33-47.

—_, "La densidad figurada del lenguaje alburero", Logo, vol. I, núm. 1, 2001, 53-60.

Fodor, Jerry A., The Modularity of Mind. An Essay on Faculty Psychology, Cambridge-London, The мIт Press, 1983.

Grice, H. Paul, "Logic and conversation" [1968], en Studies in the Way of Words, Cambridge-London, Harvard University Press, 1991, 22-40.

GUTIÉRREZ GoNZÁLEZ, Noé, La construcción interactiva del albur en Tepito. Ms. Trabajo del Seminario de Investigación III, Licenciatura en Humanidades (Lingüística), Universidad Autónoma Metropolitana-Iztapalapa, 1998.

Hernández, Julio, "Dolores”, La Jornada, Astillero, 25 de junio de $2007<$ http://www.jornada.unam.mx/2007/06/25/index.php?sect ion $=$ opinion $\&$ article $=004 \mathrm{o} 1 \mathrm{pol}>$.

__ , "Por una nimiedad", La Jornada, Astillero, 6 de septiembre de $2006<$ http://www.jornada.unam.mx/2006/09/06/index.php?sect ion $=$ opinion \&article $=004 \mathrm{o} 1 \mathrm{pol}>$.

—_ "Contrapunto", La Jornada, Astillero, 21 de noviembre de 2006 <http://www.jornada.unam.mx/2006/11/21/index.php?sec tion $=$ opinion \&article $=004 \mathrm{o} 1 \mathrm{pol}>$.

, "Fe Lee Pe", La Jornada, Astillero, 4 de julio de 2007<http:// www.jornada.unam.mx/2007/07/04/index.php?section=opinion \&article $=004 \mathrm{o} 1 \mathrm{pol}>$.

, "El partido de la esperanza (Pez)", La Jornada, Astillero, 2 de julio de $2007<$ http://www.jornada.unam.mx/2007/07/02/index. php?section $=$ opinion $\&$ article $=004 \mathrm{o} 1 \mathrm{pol}>$. 
Hernández, Julio, "Feliz es Ulipe", La Jornada, Astillero, 23 de julio de $2007<$ <ttp://www.jornada.unam.mx/2007/07/23/index.ph $\mathrm{p}$ ?section $=$ opinion $\&$ article $=004 \mathrm{o} 1 \mathrm{pol}>$.

Lara, Luis Fernando, Curso de lexicología, México, El Colegio de México, 2006.

MeL'ČUK, Igor, Vers une Linguistique sens-texte, Leçon Inaugurale de la chaire internationale faite le Vendredi 10 janvier 1997, Collège de France, 1997.

Pérez, Elvira, Julio Santiago et al., "Perceptual Bias in Speech Error Data Collection: Insights from Spanish Speech Errors", Journal of Psycholinguistic Research 36: 3, 2007, 207-235.

Puig, Luisa, "Los implícitos discursivos: un enfoque retórico", Acta Poetica 14-15, 1993-1994, 217-234.

Solmecke, Gert, Texte hören, lesen und verstehen, Berlin, Langenscheidt, 1997.

SPerber, Dan y Deidre WILSON, Relevance. Communication and Cognition [1986], Oxford-Cambridge, Blackwell, 2a ed., 1995.

Viso del, Susana, José Ma. IgoA y José E. García Albea, "On the Autonomy of Phonological Encoding: Evidence from Slips of the Tongue in Spanish", Journal of Psycholinguistic Research, 20: 3, 1991, 161-185.

Villaurrutia, Xavier, Nostalgia de la muerte (poemas y teatro), México, Fondo de Cultura Económica, 1984. 